\title{
قياس أبعاد جودة الخدمة الصحية المقدمة في مستشفيات حلب الحكومية: * دراسة مقارنة
}

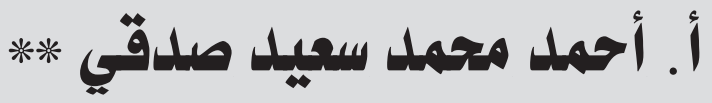

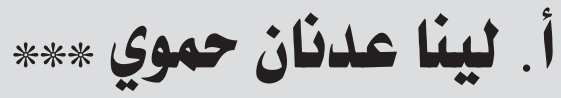

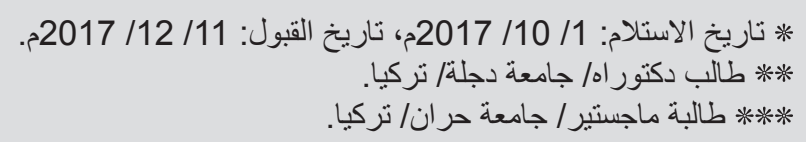


administrators) at Aleppo governmental hospitals related to their conceptions of the quality's dimensions of the health services. This is due to the variables of gender, age, and experience years. Moreover, there are significant statistical differences among service providers (doctors, nurses, administrators) at Aleppo governmental hospitals at Aleppo governmental hospitals related to their conceptions of the quality's dimensions of the health services due to the nature of the administrative work. Furthermore, there are significant statistical differences at Aleppo governmental hospitals which are affiliated to the Ministry of Health and the Ministry of Higher Education, ascribed to reliability, responsiveness, and assurance.

The most important recommendation: the need for conducting Seminars, lectures and training programs by the administration at Aleppo Governmental Hospitals, in order to enhance the quality of the offered health services, and the need for carrying out periodic surveys to determine the level of application of the health services' quality dimensions.

Key Words: Quality of the Health Services, Governmental Hospitals in Aleppo.

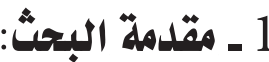

تحظى جودة الخدمة باهتمام واسع يفوق الاهتمام بجودة الدمة

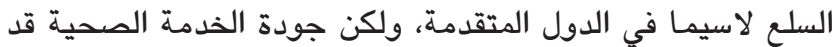

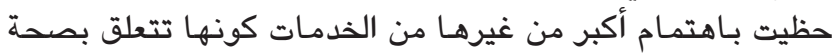

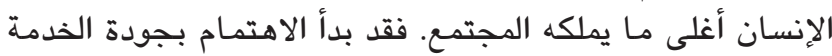

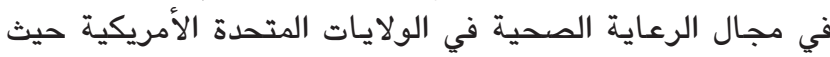

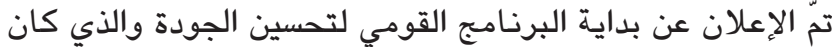

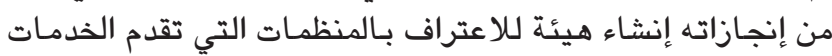
(Joint Commission for Accreditation of الصحية أطلق عليهات إنطاء Health Care Organization - JCAHO)

يواجه القطاع الصحي في الجمهورية العربية السورية عموماً

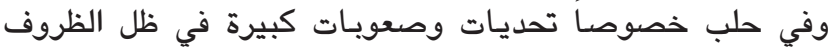

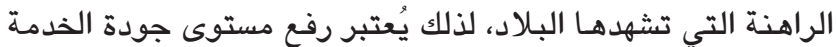

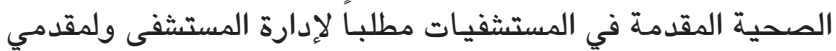

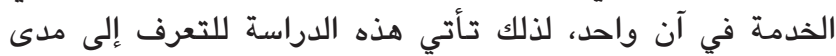

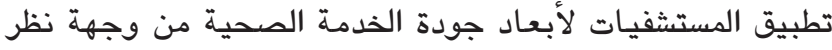

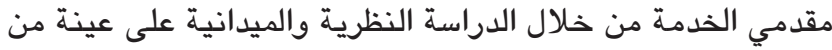

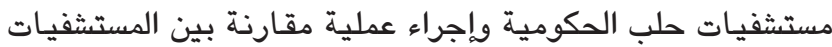

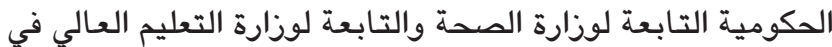

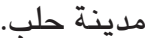

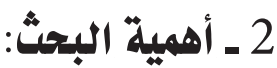

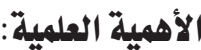

تتجلى الأهمية العلمية في أن جودة الخدمة الصحية من
يهدف هذا البحث إلى قياس أبعاد جودة الخدمة الصحية

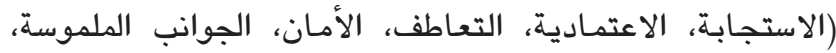

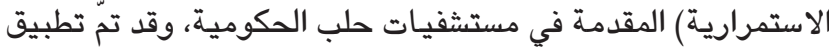

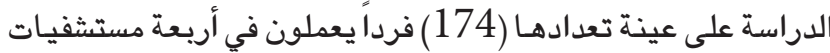

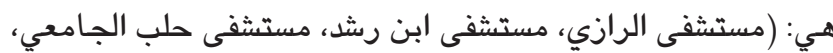

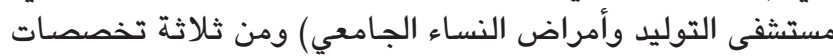
هي: (67 طبيب، 69 ممرض، وقد البرلئ 38 إداري) .

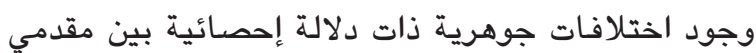

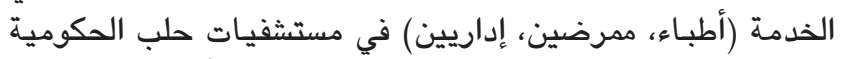

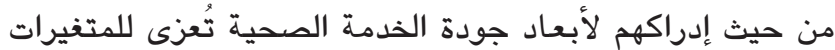
الديموغرافية التالية: (الجنس، العرر، سنوات الخبرة الخدة ) .

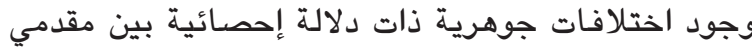

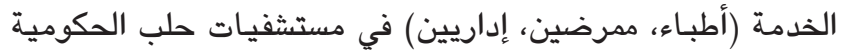

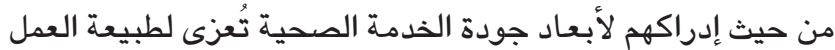

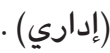

وجود اختلافات جوهرية ذات دلالة إحصائية بين مستشفيات

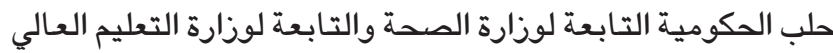

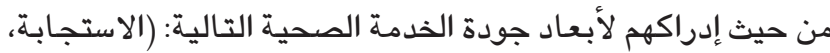

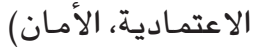

أهم التوصيات: قيام الإدارات في مستشفيات حلب الحكومية

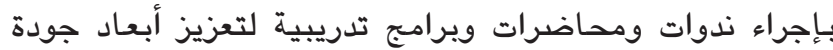

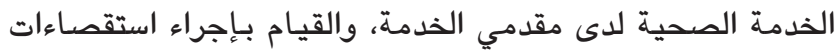
دورية لمعرفة مستوى تطبيق أبعاد جودة الخدمة الصحية والتية الكلمات المفتاحية: جودة الخدمة الصحية، المستشفيات

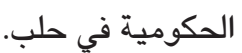

Measuring the Quality's Dimensions of the Health Services offered at Aleppo Governmental Hospitals: A Comparative Study

\section{Abstract}

This research aims at measuring the quality's dimensions of the health services (reliability, responsiveness, empathy, assurance, tangibles, continuity) offered at Aleppo governmental hospitals. The study was applied on a sample that consisted of (174) employees who work in four hospitals are: Alrazy Hospital, Ibn Rushd Hospital, Aleppo University Hospital, Aleppo University Hospital of Obst. \& Gyn. The sample included employees from different job categories, 67 doctors, 69 nurses 38 administrators.

The results of the study can be summarized as follows, there are significant statistical differences among service providers (doctors, nurses, 
الصحة ووزارة التعليم العالي؟ 5 ـ تساؤلات البحث:

1. هل هناك اختلافات في إدراك مقدمي الخدمة (أطباء،

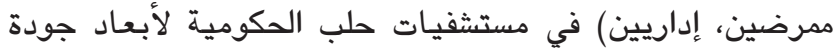
الخدمة الصحية وفقاً للخصائص الديموغرافية التالية: (الجنس، التسات

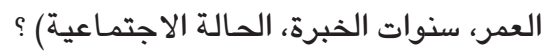

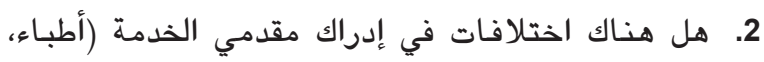

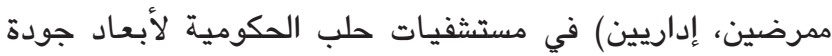

الخدمة الصحية وفقاً لطبيعة العمل (طبي، تمريضي، إداري) ؟ لإني

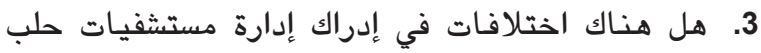
الحكومية لأبعاد جودة الخدمة الصحية تُعزى لاختلاف إداف تبعية

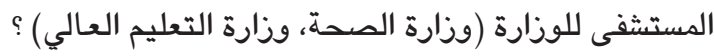

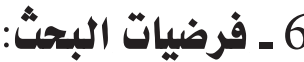

1. لا توجد اختلافات جوهرية ذات دلالة إحصائية بين

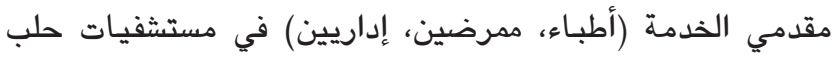

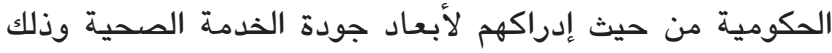

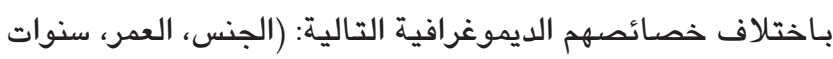

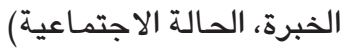

2. لا توجد اختلافات جوهرية ذات دلالة إحصائية بين

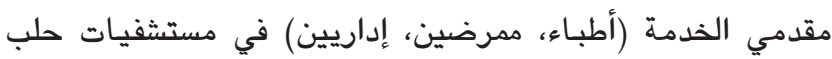

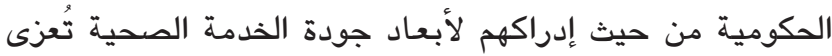

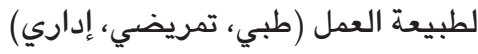

3. لا توجد اختلافات جوهرية ذات دلالة إحصائية بين إدارة

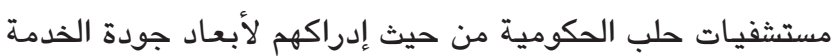

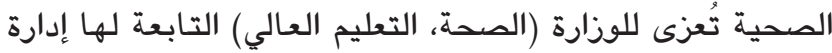

المستشفى.

\section{7 ـ مجتمع البحث وعينته:}

يتكون مجتمع البحث من مقدمي الخدمة (أطباء، ممرضين، إداريين) في مستشفيات حلب الحكومية:

1. مستشفيات حلب الحكومية التابعة لوزارة الصحة:

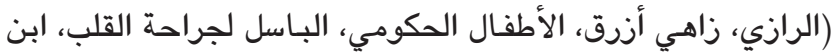

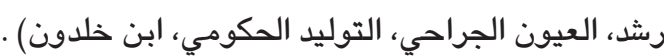
2. مستشفيات حلب الحكومية التابعة لوزارة التعليم العالي: (حلب الجامعي، الكندي الجامعي، جراحة القلب الجامعي، جراحة

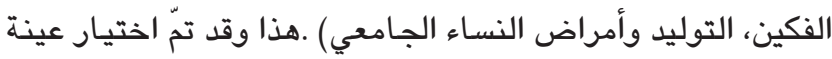

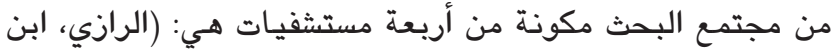
رشد، حلب الجامعي، التوليد وأمراض النساء الجامعي) .

$$
\text { والجدول رقم (1) يوضح مجتمح البحث: }
$$

الأبحاث الهامة والمفيدة لأي مستشفى يهتم بتقديم خدماته

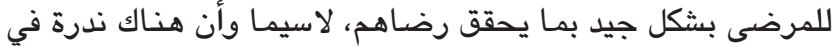
الدراسات التي بحثت في قياس أبعاد جودة الخدمة الصحية في

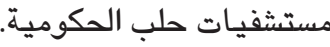

\section{الأهمية العملية: تتمثل الأهمية العملية بما يلي:}

• تطبيق هذه الدراسة على مستشفيات حلب الحكومية التي تُعتبر من المستشفيات السورية الهامة التي تستحق الاهتمام

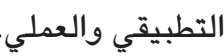

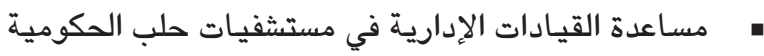

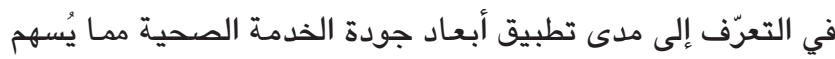
في تحسين جودة هذه الخدمات.

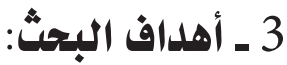

يتمثل الهدف الرئيسي للبحث في قياس أبعاد جودة الخدمة

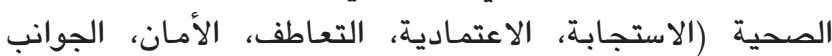

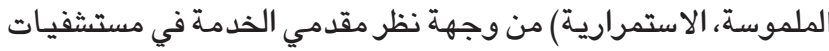
حلب الحكومية، ويتفرع منه الأهداف التالية:

• التعرف إلى مدى تطبيق مستشفيات حلب الحكومية لأبعاد

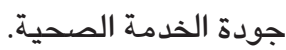

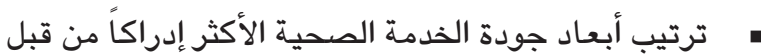

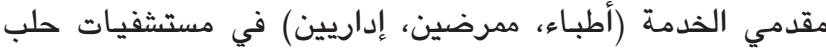

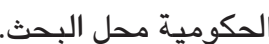

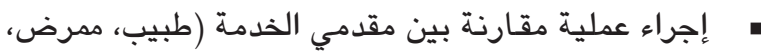

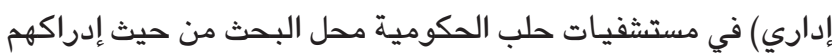
ل الأبعاد جودة الخدمة الصحية. • إجراء عملية مقارنة بين مستشفيات حلب الحكومية التابعة لوزارة الصحة والتابعة لوزارة التعليم العالي في هدى بـى تطبيق أبعاد جودة الخدمة الصحية. • تقديم مجموعة من التوصيات والمقترحات للقيادات الإدارية في مستشفيات حلب الحكومية لمدى تطبيق أبعاد جودة الترديات

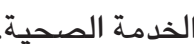
4 ـ مشكالة البحثة: تتجلى مشكلة البحث في ضعف قدرة مستشفيات حلب

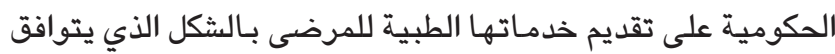

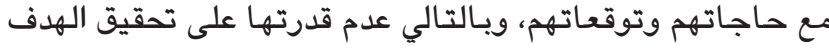

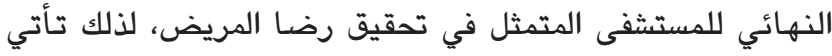

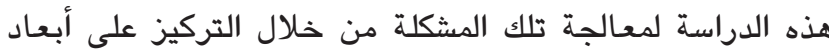

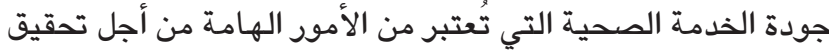
رضا المرضى، ويمكن صياغة مشكلة البحث في التساؤل التالي: ما دلى توفر أبعاد جودة الخدمة الصحية (الاستجابة، الاعتمادية، التعاطف، الأمان، الجوانب الملموسة، الاستمراريةة)

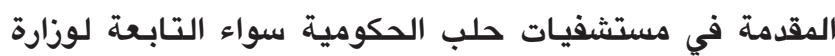




\begin{tabular}{|c|c|c|c|c|c|c|c|c|c|}
\hline \multicolumn{10}{|c|}{ جدول رقم (1) : } \\
\hline \multicolumn{8}{|c|}{ مقدمي الخدمة ونسبتهم المئوية } & \multirow{2}{*}{ اسم الوزارة } & \multirow{2}{*}{ اسم المستشفى } \\
\hline$\%$ & 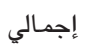 & $\%$ & إداريين & $\%$ & مدرضين & $\%$ & أطباء & & \\
\hline $39 \%$ & 599 & $6 \%$ & 33 & $32 \%$ & 192 & $62 \%$ & 374 & الصحة & 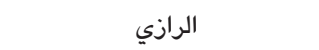 \\
\hline $13 \%$ & 196 & $35 \%$ & 69 & $29 \%$ & 56 & $36 \%$ & 71 & الصحة & ابن رشد \\
\hline $43 \%$ & 663 & $27 \%$ & 181 & $49 \%$ & 327 & $24 \%$ & 155 & 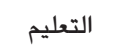 & حلب الجامعي \\
\hline $5 \%$ & 70 & $20 \%$ & 14 & $54 \%$ & 38 & $26 \%$ & 18 & 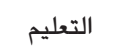 & التوليد وأمراض النساء الجامعي \\
\hline $100 \%$ & 1528 & $19 \%$ & 297 & $40 \%$ & 613 & $41 \%$ & 618 & & الإجمالي \\
\hline
\end{tabular}

المصدر: قسم الإحصاء في وزارة الصحة ومركز المعلومات والتوثيق في مستشفيات جامعة حلب (2016)

\begin{tabular}{|c|c|c|c|}
\hline استمارات بكل & طبيعة & استمارات كل & اسم المستشفى \\
\hline $32=24 \% * 132$ & طبيب & & \\
\hline $65=49 \% * 132$ & ممرض & $\begin{array}{c}=(43 \% * 306) \\
132\end{array}$ & حلب الجامعي \\
\hline $35=27 \% * 132$ & إداري & & \\
\hline $4=26 \% * 15$ & طبيب & & \\
\hline $8=54 \% * 15$ & ممرض & $\begin{array}{c}=(5 \% * 306) \\
15\end{array}$ & النساء الجامعيد وأمراض \\
\hline $3=20 \% * 15$ & إداري & & \\
\hline
\end{tabular}

المصدر: من إعداد الباحث (الدراسة الميدانية) .

هذا وقد تمّ استرداد (212) قائمة استقصساء منها (38) قائمة استقصاء غير صالحة للتحليل، أي تمّ الحصول على (174) تحائمة

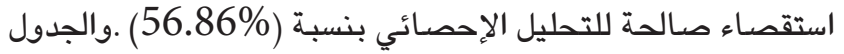
رقم (3) يوضح ذلك:

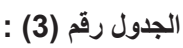

\begin{tabular}{|c|c|c|c|}
\hline الاستمارات & الاستمارات & طبيعة العمل & اسم المستشفى \\
\hline 35 & 74 & طبيب & \\
\hline 22 & 38 & ممرض & الرازي \\
\hline 5 & 7 & إداري & \\
\hline 9 & 14 & طبيب & \\
\hline 8 & 12 & ممرض & ابن رشد \\
\hline 9 & 14 & إداري & \\
\hline 21 & 32 & طبيب & \\
\hline 34 & 65 & مدرض & حلب الجامعي \\
\hline 23 & 35 & إداري & \\
\hline
\end{tabular}

وقد تمّ اختيار عينة من مجتمع البحث بـاستخدام المعادلة

التالية (علي، 1994، صدمبار عينة من مجن :

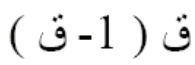

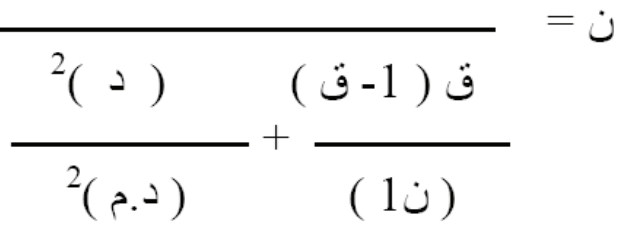

حيث:

(ن) : حجم العينة، (ق) : نسبة الحد الأقصى لتوافر

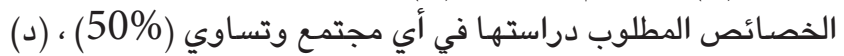

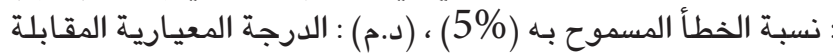

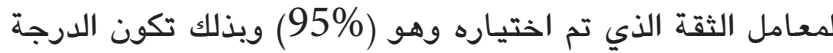

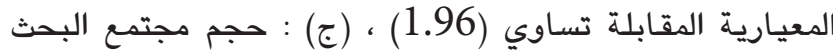

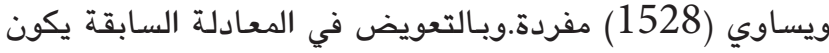
حجم العينة (306) مفردة. حيث تمّ توزيع (306) قائمة استقصاء على مقدمي الخدمة

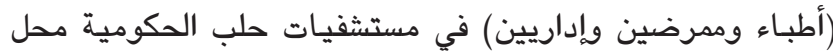
البحث.والجدول رقم (2) يوضح ذلك: وادئ فئ

$$
\text { جدول رقم (2) : جدابا }
$$

الاستمارات لكل مستثفى حسابياً وتوزيعها على كل تخصص بكل مستثفى حسابياً

\begin{tabular}{|c|c|c|c|}
\hline استمارات بكل & طبيعة & استمارات كل & اسم المستشفى \\
\hline $74=62 \% * 119$ & طبيب & & \\
\hline $38=32 \% * 119$ & ممرض & $\begin{array}{c}=(39 \% * 306) \\
119\end{array}$ & ال الرازي \\
\hline $7=6 \% * 119$ & إداري & & \\
\hline $14=36 \% * 40$ & طبيب & & \\
\hline $12=29 \% * 40$ & مدرض & $\begin{array}{c}=(13 \% * 306) \\
40\end{array}$ & 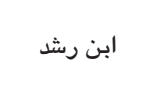 \\
\hline $14=35 \% * 40$ & إداري & & \\
\hline
\end{tabular}




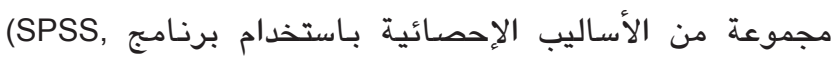

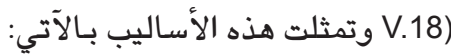
• معامل كرونباخ ألفا (Cronbach's). • توزيع مفردات العينة وذلك من حيث العدد والنسبة

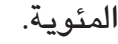
• الإحصاءات الوصفية (الوسط الحسابي والانحراف

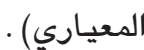
• أسلوب تحليل التباين الأحادي (One - Way ANOVA) .

$$
\text { • اختبار (T- Test) لعينتين مستقلتين. }
$$

\section{0 ـ منهجية البحث:}

تقوم منهجية البحث على الجمع بين الدراسة النظرية

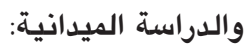

1. الدراسة النظرية: اعتمد الباحث على الدنهج الوصفي

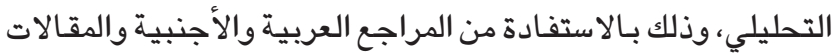

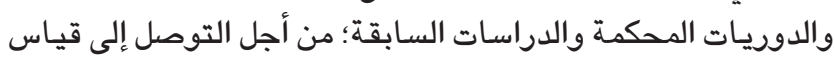
أبعاد جودة الخدمة الصحية الدقدمة في مستشفيات حلب الحكوات التحمية. 2. الدراسة الميدانية: وتهدف إلى قياس أبعاد جودة الخدمة الصحية المقدمة في مستشفيات حلب الحكومية، وذلك من خلية خلال توزيع قائمة استقصاء وتفريغها وتحليلها.

\begin{tabular}{|c|c|c|c|}
\hline الاستمارات & الاستمارات & طبيعة العمل & اسم المستشفى \\
\hline 2 & 4 & طبيب & \\
\hline 5 & 8 & ممرض & النساء الجامعي وأمراض \\
\hline 1 & 3 & إداري & \\
\hline 174 & 306 & \multicolumn{2}{|c|}{ الإجمالي } \\
\hline
\end{tabular}

المصدر : من إعداد الباحث (الدر اسة الميدانية) .

\section{8 ـ أسلوب جمع البياثات:}

تم جمع البيانات الأساسية بواسطة أداة خاصة تمثلت بقائمة

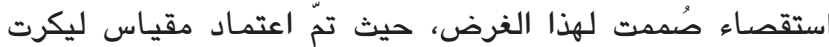

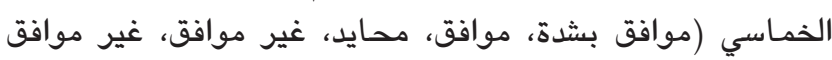

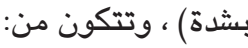

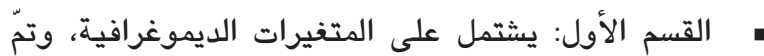
قياسها باستخدام (4) أسئلة.

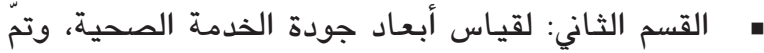
استخدام مقياس مكوّن من (18) عبارة، بواقع ثلاث عبارات لكل بُعد. 9 ـ أسلوب تتليل البيانات: تمّ تحليل البيانات واختبار صحة الفروض بالاعتماد على 11 ـ نهوذج البحث:

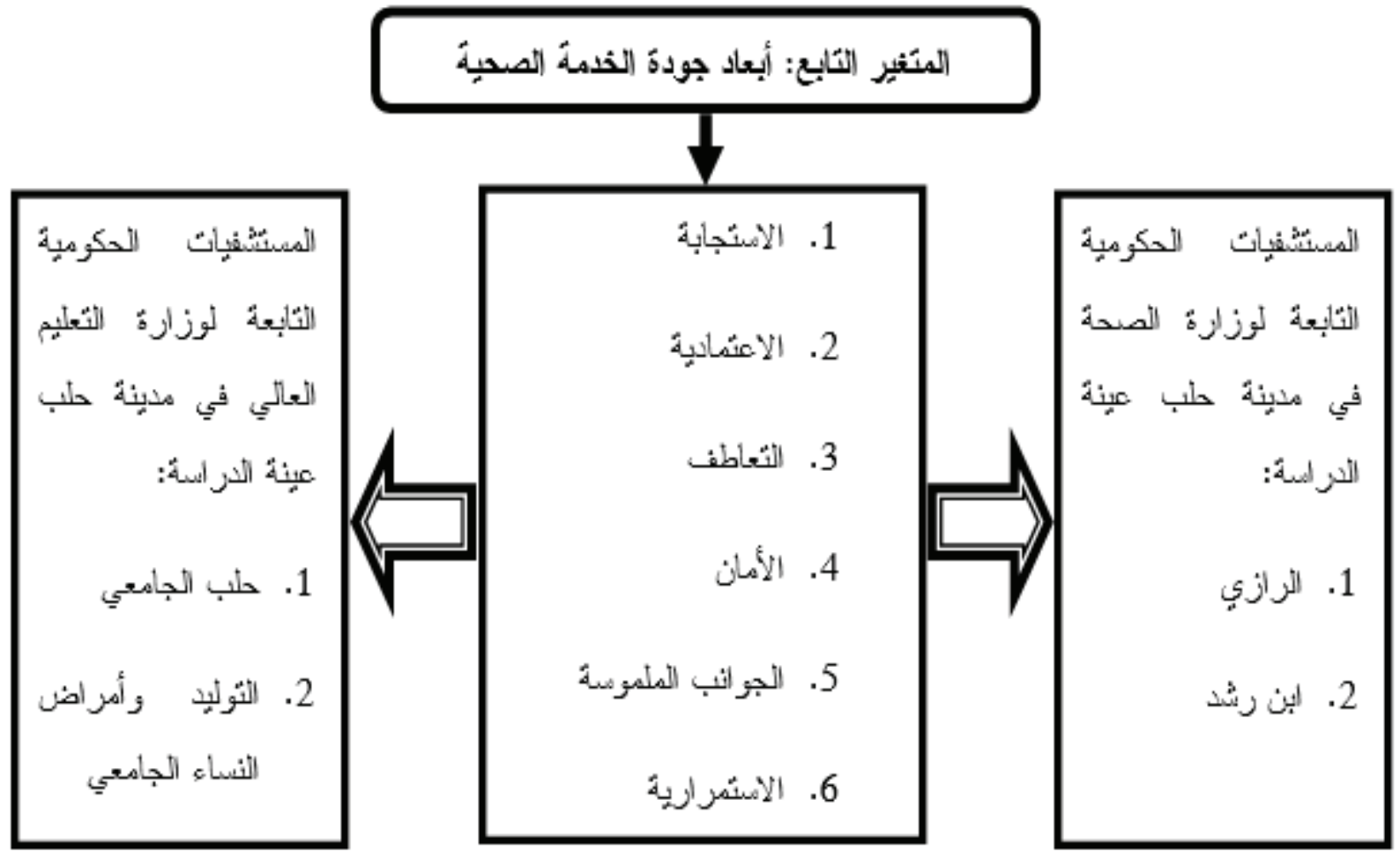




\section{" ضمان الصحة البدنية للمستفيدين.}

• تقديم خدمة صحية ذات جودة مميزة من شأنها تحقيق

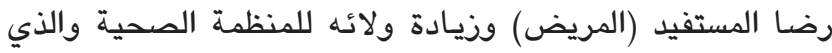

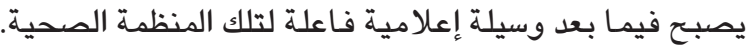

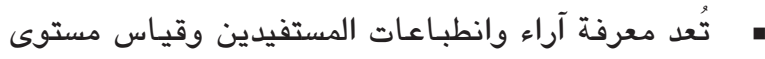

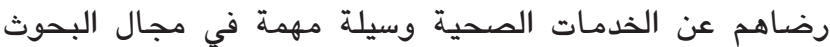
الإدارية والتخطيط للرعاية الصحية ووضـع السياسات المتعلقة بها. • تطوير وتحسين قنوات الاتصال بين المستفيدين من الخدمة الصحية ومقدميها.

• تمكين المنظمات الصحية من تأدية مهامها بكفاءة وفاعلية.

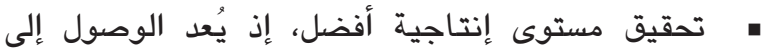

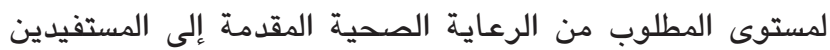
(المرضى) الهدف الأساسي من تطبيق الجودة. • كسب رضـا المستفيد (المريض) ، إذ يُعد أن هناك قيماً

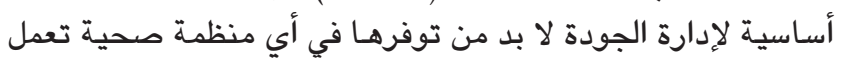
على تحسين الجودة وتسعى لتطبيق نظم الجودة ويـالتالي تطوير أدي أداء العمل ويـالنهاية كسب رضـا المستفيل.

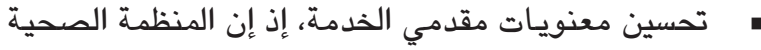

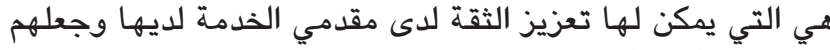

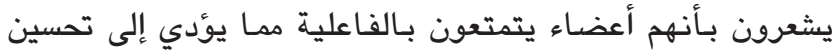

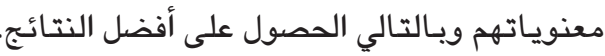

\section{Q أبعاد جودة الخدمة الصحية -}

:mensions

هناك الكثير من الدراسات التي تناولت أبعاد جودة الخدمة

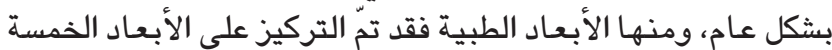

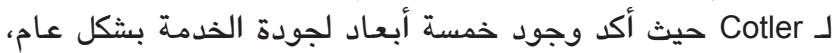

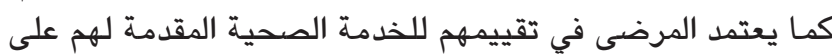
أساس نوعية الخدمة، بـاعتمادهم على نقيم نفس الأبعاد وهي (ذيـاب، (75، 2012

• الاستجابة (Reliability) : المساعدة الحقيقة في تقديم

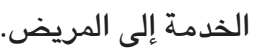

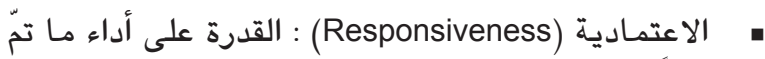
تحديده مسبقاً وبشكل دقيق.

• التعاطف (Empathy) : درجة الاهتمام والرعاية الشخصية تجـاه المريض.

• الأمان (Assurance) : هي الصفات التي يتصف بها العاملون من معرفة وقدرة على تقديم الخدمة.

• الجوانب الملموسة (Tangibles) : التسهيلات المادية والتجهيزات والمظهر الخارجي للعاملين.

بينما يرى Brown et al أن جودة الخدمة الصحية الأساسية تُعتبر طريقة للتفكير حول رعاية المريض، مـا هو المهم بـالنسبة النها

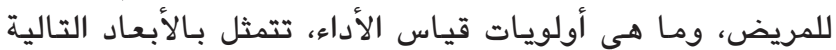

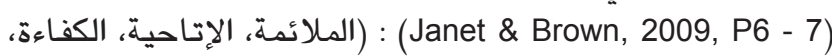

\section{2}

• اقتصرت الدراسة على الأبعاد الخمسة لجودة الخدمة

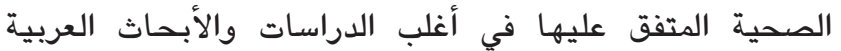

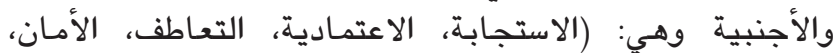

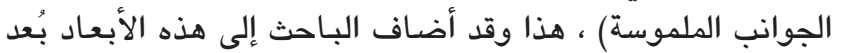

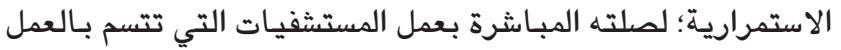
المتواصل وتقديم خدماتها على مدار 24 ساعة في اليوم.

• اقتصر البحث على مقدمي الخدمة فقط (أطباء، ممرضين،

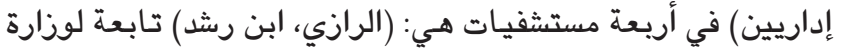

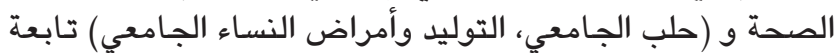

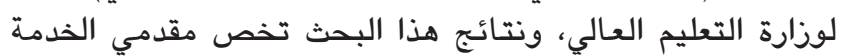

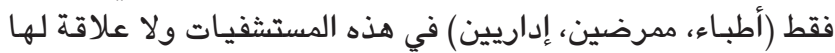

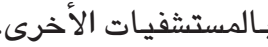
• تمّ إجراء الدراسة الميدانية في الفترة بين 15 15/ 10 1016/

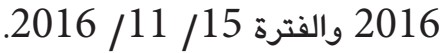
• تمّ استخدام مستوى ثقة (95\%) في اختبار صحة الفروض وتعديم النتائج.

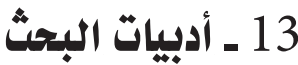

1 ـ جودة الخدمة الصحية Quality of Health Service:

يُعتبر من الصعب التعبير عن جودة الخدمة بكميات محددة

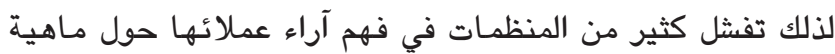

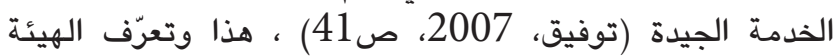

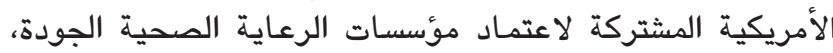

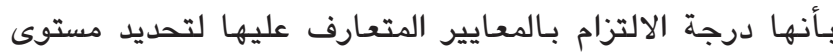

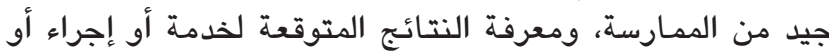

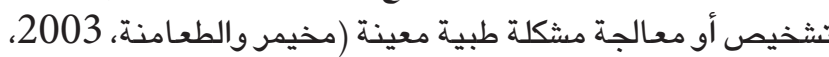

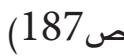

ويرى Qvertveil بأنه إذا كانت جودة الخدمة هي مقابلة

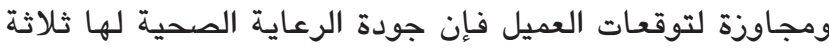
أبعاد هي (Qvertveil, 2000, P75) :

• الجودة من وجهة نظر متلقي الخدمة: وهي إذا كانت الخدمات المقدمة هي المرغوية.

• الجودة من وجهة نظر مقدمي الخدمة: وهي إذا كانت

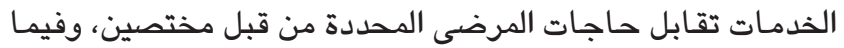

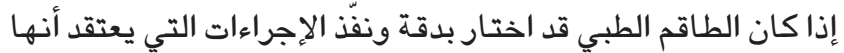

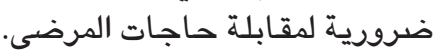
• الجودة من وجهة نظر الإدارة: وتعني استخدام للموارد المتاحة من أجل مقابلة حاجات المرضى.

Aims of Quality of Health أهداف جودة الخدمة الصحية

:Service

يرى خوجة أن أهداف جودة الخدمة الصحية تتمثل بما يلي (خوجة، 2003، صوحة 221) : 


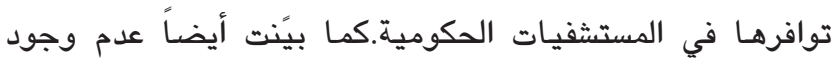
فروقات ذات دلالة إحصائية لمستويات جودية الحية الخدمات الخدات الصحية

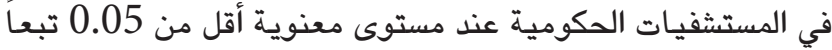

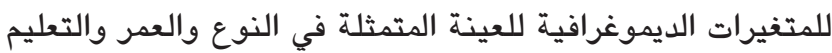

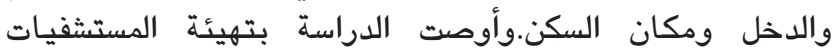

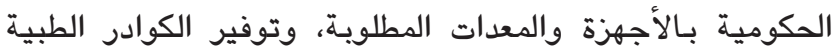

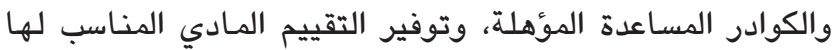

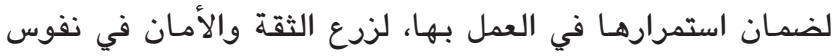

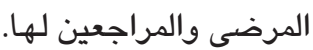

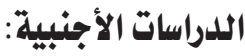

(Lim \& Tang, 2000) (رراسة: (1)

هدفت هذه الدراسة إلى التركيز على جودة الخدان التمة في

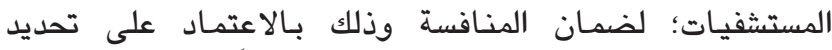

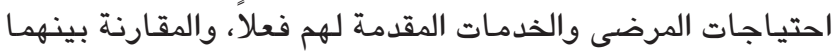

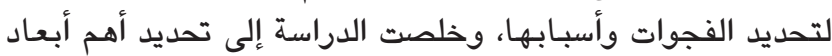

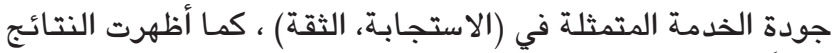

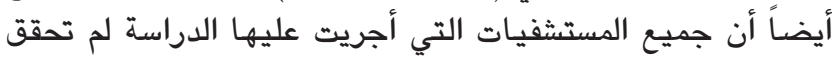
توقعات المرضى.

(Talluru \& Prasad, 2003) (دراسة)

هدفت هذه الدراسة إلى دراسة العوامل المؤثرة في رضا

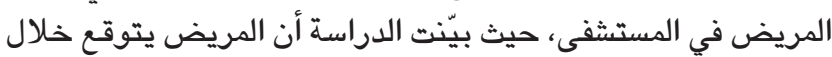

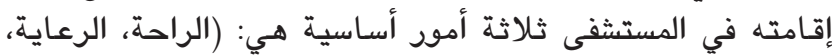

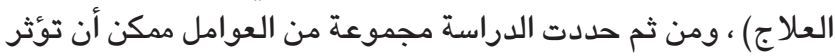
في مستوى رضا المريض في هي: - الاعتمادية: وتعني قدرة الدستشفى على أداء الخدمات التي يتوقعها المريض بدقة وإتقان.

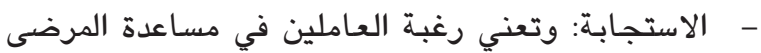

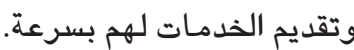

- - سلوك العاملين: وتعني امتلاك العاملين اللباقة في سلوكهم وتعاملهم الذي يمنح الثقة للمريض. - التعاطف: ويعني أن يُبدي العاملون استعداداً واضحاً للتعاطف والاهتمام بالمرضى كل على حدى.

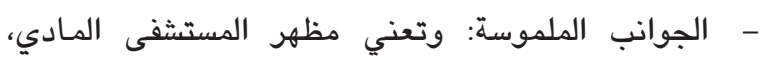
التجهيزات والمعدات والمواد ووسائل الاتصال.

دراسة (Gupta \& Denton, 2008) :

هدفت هذه الدراسة إلى دراسة العوامل المؤثرة في طريقة

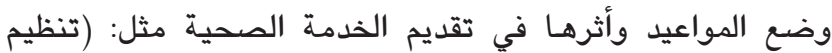

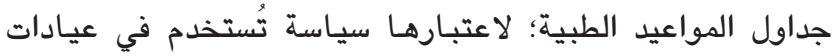

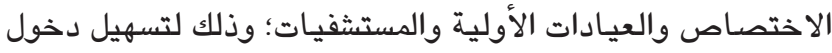

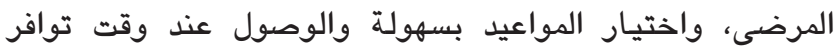

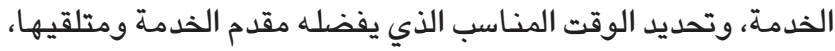

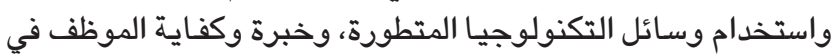

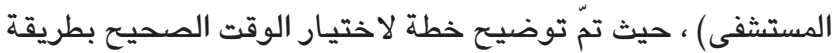
علمية وعملية تنظم جداول المواعيد.
الاستمرارية، الفعالية، الوقاية - الكثف المبكر، الاحترام، الأمان) .

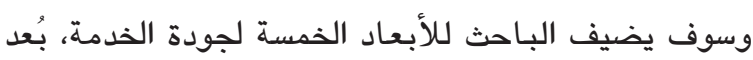

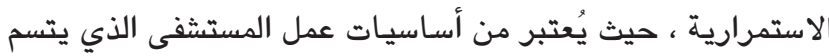

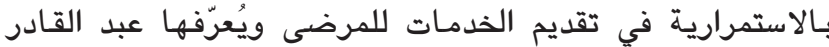

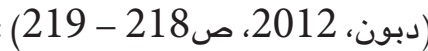

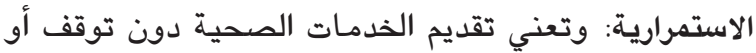
انقطاع، على أن تُصمم هذه الخدمات على تلى أساس مبدأ الاستمرارية

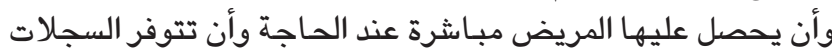

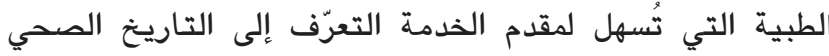

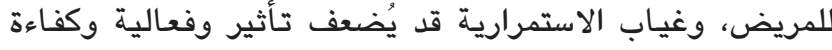
الخدمة ويقلل من ضمان الجودة.

14

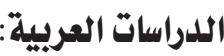

$$
\text { دراسة (الفراج، 2009) : }
$$

هدفت هذه الدراسة إلى كثف جودة الرعاية الصحية المُقدمة في المستشفيات التعليمية السورية للمرضى ومن وجهة التهاتية نظرهم. وخلص البحث إلى النتائج التالية:

- - كفاءة الطبيب المهنية في المستشفى نفسه التي يقصدها

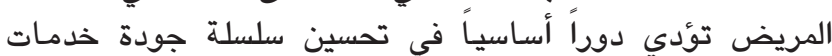

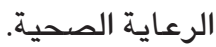

- تُشكل سرعة استجابة المستشفى لاحتياجات المريض المرئ عاملاً مهماً في خلق رضا عال لدى المريض.

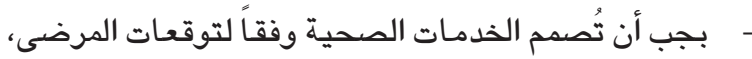
لأن هذا يُعد حجر الزاوية في تطوير الخدمات المتوافقة مع آمال

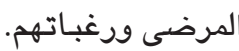
دراسة (الرواشدة \& الصمادي، 2010)

هدفت هذه الدراسة إلى معرفة مستوى الخدمات الصحية الصدالية

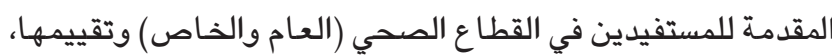
من خلال قياس متغيرات تتعلق بمستوى الخدمات الصدية الصدية (إجراءات

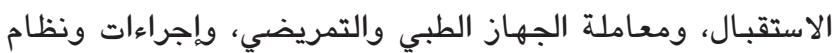

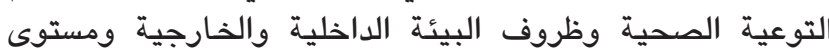

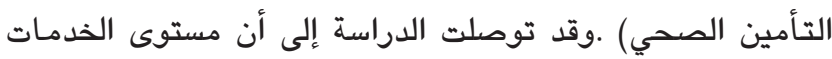

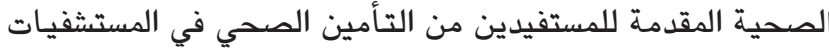

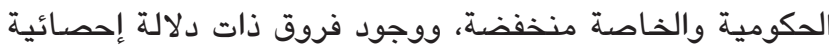

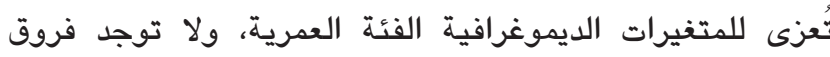

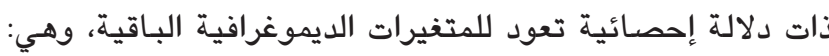

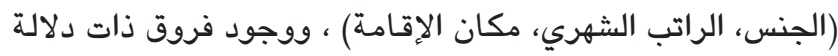

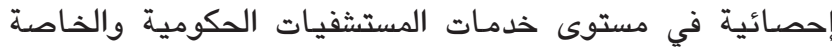
تُعزى لصالح القطاع الخاص.

$$
\text { دراسة (عبد القادر، 2015) }
$$

هدفت هذه الدراسة إلى قياس مستوى جودة الخدمة الصحية

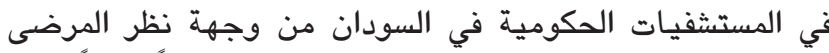

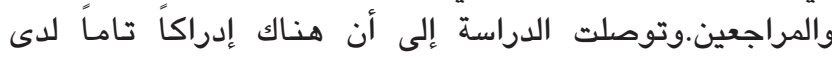

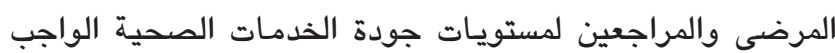




\begin{tabular}{|c|c|c|c|}
\hline النسبة المئوية \% \% & 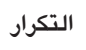 & الفئات & المتغير الديموغرافي \\
\hline 13.8 & 24 & 25 سنة فأقل & \multirow{5}{*}{ العمر } \\
\hline 27 & 47 & من 26 إلى 35 سنة & \\
\hline 46.6 & 81 & من 36 إلى 45 سنة & \\
\hline 12.6 & 22 & أكثر من 45 سنة & \\
\hline 17.8 & 31 & 5 سنوات فأقل & \\
\hline 50.6 & 88 & من 6 إلى 10 سنوات & \multirow{3}{*}{ سنوات الخبرة } \\
\hline 20.1 & 35 & من 11 إلى 15 سنة & \\
\hline 11.5 & 20 & أكثر من 15 سنة & \\
\hline 31.6 & 55 & أعزب & \multirow{2}{*}{ الحالة الاجتماعية } \\
\hline 68.4 & 119 & متزوج & \\
\hline 100 & 174 & \multicolumn{2}{|c|}{ المجموع الكلي لأفراد العينة } \\
\hline
\end{tabular}

3 ـ الإحصاءات الوصفية لمتفيرات البحث:

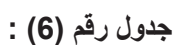

\begin{tabular}{|c|c|c|c|c|}
\hline \multicolumn{5}{|c|}{ الوسط الحسابي والانحر اف المعياري لمتغيرات البحث } \\
\hline المتغيرات & المعياري & الحسابي & العبارات & 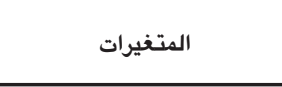 \\
\hline 2 & 0.744 & 3.89 & 3 & الاستجابة \\
\hline 5 & 0.886 & 3.60 & 3 & الاعتمادية \\
\hline 1 & 0.664 & 4.12 & 3 & التعاطف \\
\hline 4 & 0.842 & 3.64 & 3 & 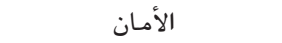 \\
\hline 6 & 0.922 & 3.45 & 3 & الجوانب الملموسة الجوس \\
\hline 3 & 0.787 & 3.77 & 3 & الاستمرارية \\
\hline-- & 0.792 & 3.75 & 18 & أبعاد جودة الخدمة الصحية \\
\hline
\end{tabular}

$$
\text { يتضح من الجدول رقم (6) ما يلي: }
$$

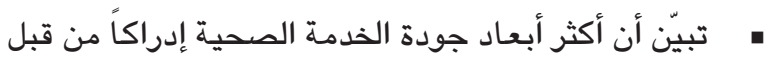

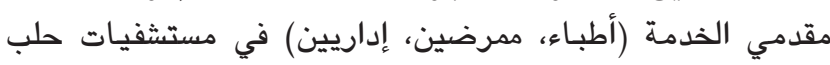

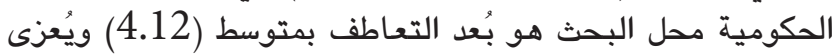

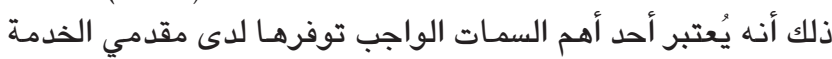

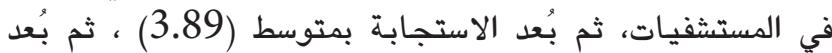

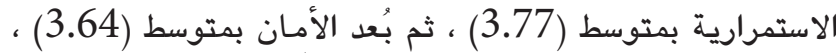
ثم بُعد الاعتمادية بمتوسط (3.60) وأخيراً بُعد الجوانب الملموسة

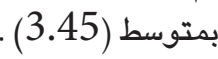

• •

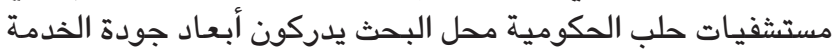

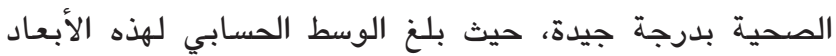
مجتمعة (3.75) بانحراف معياري (0.792) .وهذه النسبة تدل لـال على: - - توفر درجة جيدة من الرعاية لدى مقدمي الخدمة في

\section{وبعل عرض الدراسات السابقة:}

تبيّن أن هذه الدراسات اعتمدت على قياس أبعاد جودة الخدمة

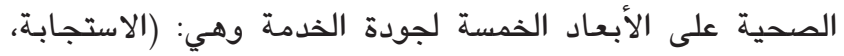

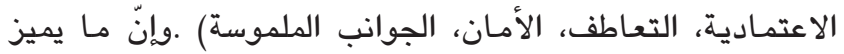

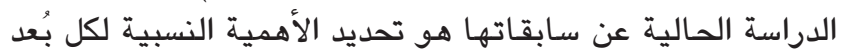

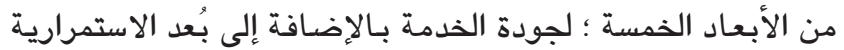

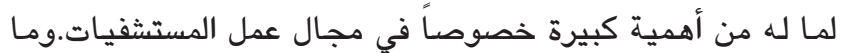
يضفي أهمية خاصة لهذه الدراسة هو: في ندرة الأبحاث والدراسات

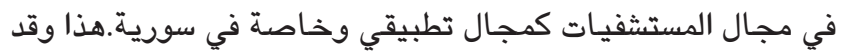
استفاد الباحث من الدراسات السابقة في تكوين الخلفية النظرية فئسية

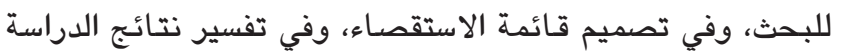

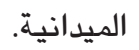

\section{5 ـ تتائج التحليل الإحصائي واختبار الفرضيات:}

\section{1 ـ ا متبار صلدق وثبات المقياس:}

اعتمد الباحث طريقة كرونباخ ألفا لحساب ثبات المقاييس

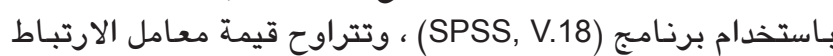

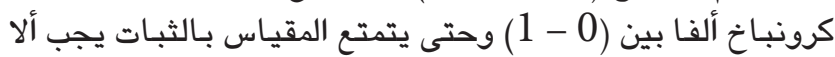

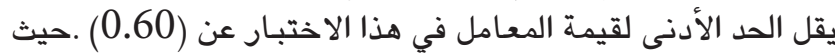

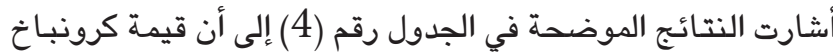

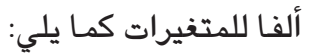
جدول رقم (4) :

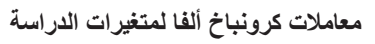

\begin{tabular}{|c|c|c|}
\hline عدد العبارات & معامل ألفا كرونباخ & المتغير \\
\hline 3 & 0.864 & الاستجابة \\
\hline 3 & 0.787 & الاعتمادية \\
\hline 3 & 0.887 & التعاطف \\
\hline 3 & 0.811 & الأمان \\
\hline 5 & 0.766 & الجوانب الملموسة \\
\hline 3 & 0.823 & الاستمرارية \\
\hline 18 & 0.898 & أبعاد جودة الخدمة الصحية \\
\hline
\end{tabular}

يبيّن الجدول رقم (4) أن قيم كرونباخ ألفا تتراوح بين

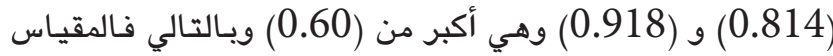
الستخدم يتسم بالثبات الداخلي لعباراتها.

\section{2 ـ وصف خصائص العينة:} جدول رقم (5) :

توزيع مفردات العينة طبقاً للمتغيرات الديموغرافية (5اتة

\begin{tabular}{|c|c|c|c|}
\hline النسبة المئوية \% & التكرار & الفئات & المتغير الديموغرافي \\
\hline 43.7 & 76 & ذ كر & \\
\hline 56.3 & 98 & أنثى & \\
\hline
\end{tabular}


(الحالة الاجتماعية) .بينما يتم رفض هذه الفرضية جزئياً فيما

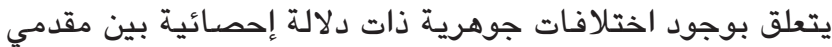

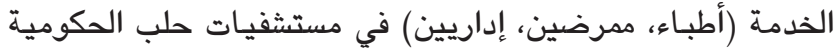

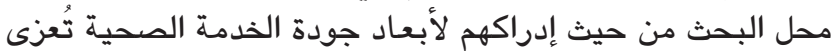

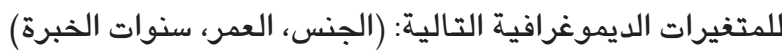
نستنتج هما سبق أن هذا البحث يتفق مع دراسة (الرواشدة

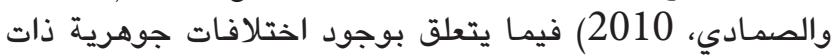

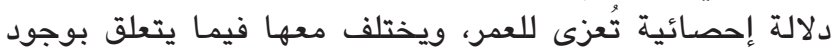
اختلافات جوهرية ذات دلالة إحصائية تُعزى للجنس.

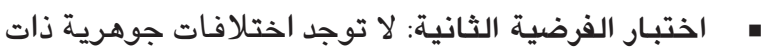

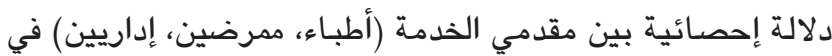

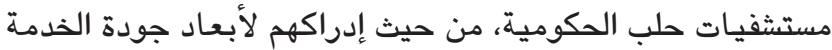

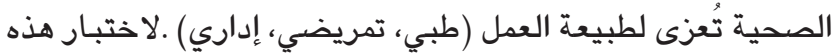

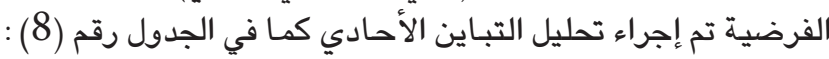

$$
\text { جدول رقم (8) : }
$$

ختبار تحليل التباين الأحادي لأبعاد جودة الذدمة الصحية وفقاً لطبيعة العمل

\begin{tabular}{|c|c|c|c|}
\hline الدلالة الاحصائية & مستوى المعنوية & قيمة F & المتغير \\
\hline غير معنوية & 0.878 & 0.038 & طبي \\
\hline غير معنوية & 0.846 & 0.044 & تمريضي \\
\hline معنوية & 0.032 & 3.221 & إداري \\
\hline
\end{tabular}

$$
\text { يتضح من الجدول رقم (8) ما يلي: }
$$

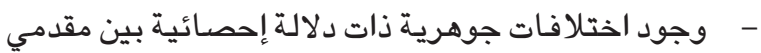

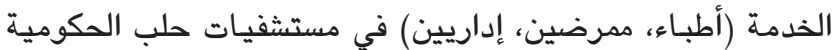

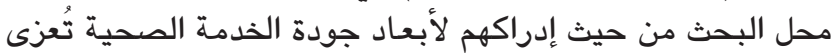

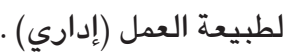

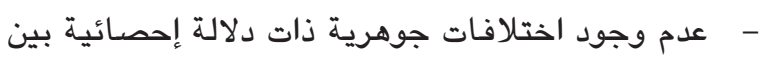

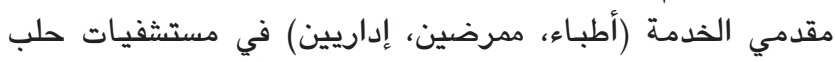

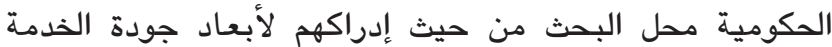

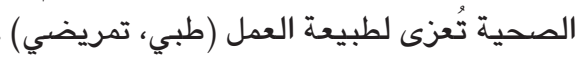

ويناءُ على نتائج التحليل السابقة: يتم قبول الفرضية

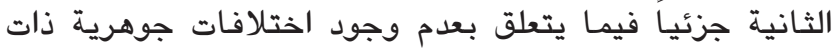

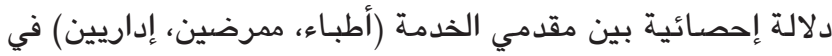
مستشفيات حلب الحكومية محل البحث ، من حيث إدمدة إدراكهم لأبعاد

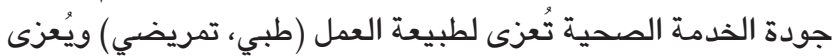

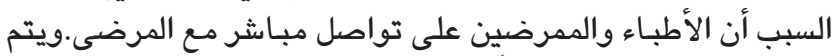
رفض هذه الفرضية جزئياً فيما يتعلق بوجود اختلافينات جواهل

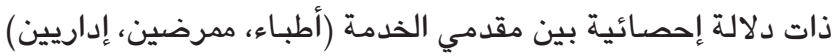

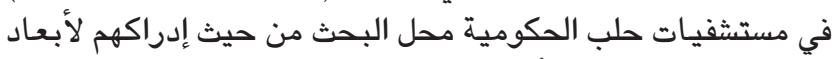

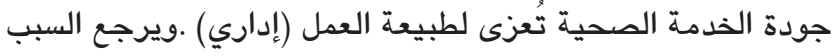

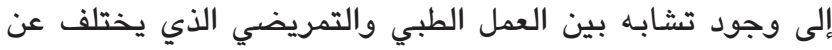
العمل الإداري في المستشفيات. نستنتج مدا سبق أن هذا البحث يتفق مع دراسة (الفراج،

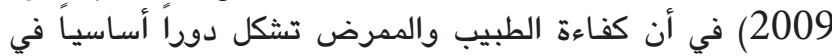

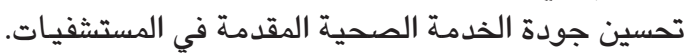

المستشفيـات عينة البحث تجاه المرضى.

- ـ توفر الرغبة لدى مقدمي الخدمة في المستشفيات عينة

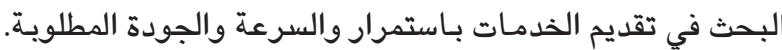

نستنتج مها سبق أن هذا البحث يتفق مع دات دراسة

(Lim \& Tang, 2000) أبعاد جودة الخدمة الصحية المقدمة في المستشفيات.

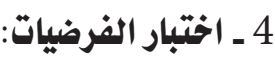

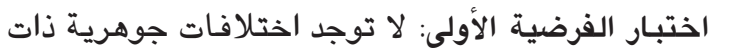

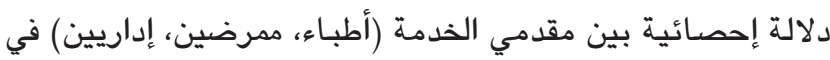

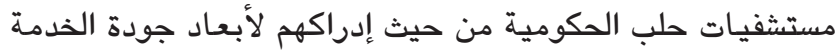

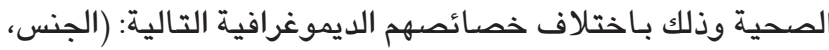

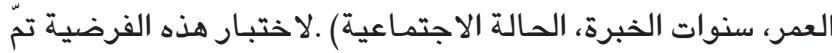

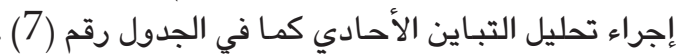

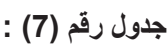

\begin{tabular}{|c|c|c|c|}
\hline الدلالة الإحصائية & مستوى المعنوية & قيمة F & المتغير \\
\hline معنوية & 0.024 & 2.332 & 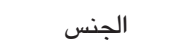 \\
\hline معنوية & 0.030 & 3.234 & العمر \\
\hline غير معنوية & 0.421 & 0.642 & الحالة الاجتماعية \\
\hline معنوية & 0.027 & 3.432 & سنوات الخبرة \\
\hline
\end{tabular}

تحليل التباين الأحادي لأبعاد جودة الخدمة الصحية وفقاً للمتغيرات اللايموغرافية

$$
\text { يتضح من الجدول رقم (7) ما يلي: }
$$

- وجود اختلافات جوهرية ذات دلالة إحصائية بين مقدمي

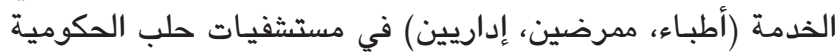

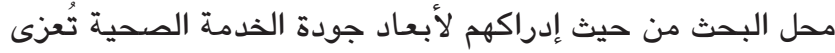
للمتغيرات الديموغرافية التالية: (الجنس، العمر، سنوات الدات الخبرة)

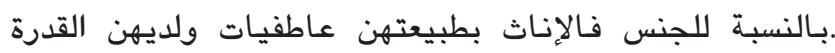

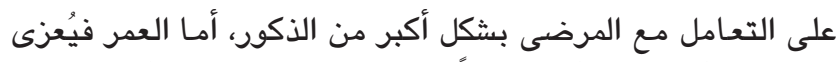

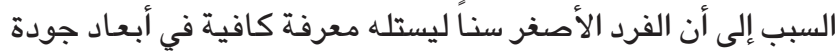

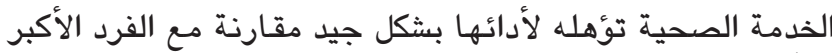

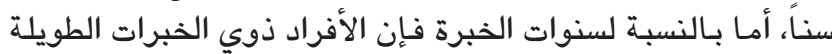

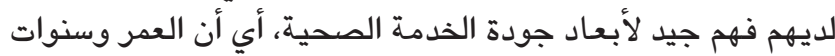
الخبرة مرتبطان ببعضهما والعلاقة بينهما علاقة طردية.

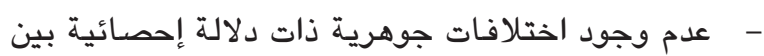

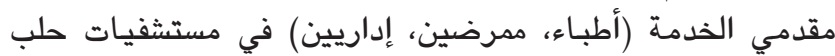

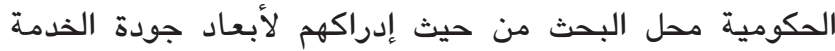
الصحية تُعزى للمتغيرات الديموغرافية التالية: (الحالة الاجتماعية الاعية)

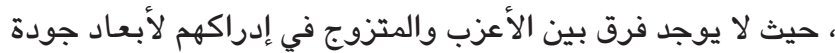

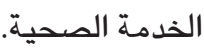

ويناءُ على نتائج التحليل السابقة: يتم قبول الفرضية

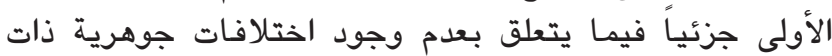

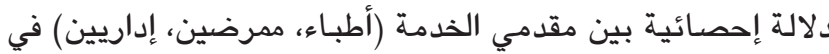

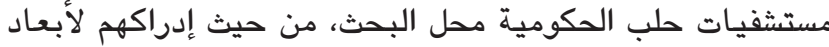

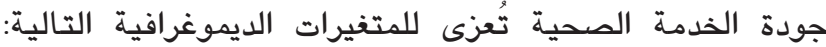




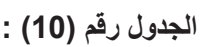

نتائج اختبار T - Test لأبعاد جودة الخدمة الصحية حسب التبعية

\begin{tabular}{|c|c|c|c|c|c|c|}
\hline \multirow{2}{*}{$\bar{y}$} & \multirow{2}{*}{ المعنويـة } & \multirow{2}{*}{ قيمة } & \multirow{2}{*}{ العينتين } & \multicolumn{2}{|c|}{ اختبار ليفين } & \multirow{2}{*}{ المتغير } \\
\hline & & & & المعنوية & $F$ & \\
\hline معنوية & 0.010 & $2.610-$ & تساوي & 0.000 & 15.233 & الاستجابة \\
\hline معنوية & 0.009 & 2.656 & تساوي & 0.072 & 3.077 & الاعتمادية \\
\hline غعنوية & 0.321 & 1.038 & تساوي & 0.540 & 0.244 & التعاطف \\
\hline معنوية & 0.012 & $2.491-$ & تساوي & 0.634 & 0.087 & الأمـان \\
\hline غعنوية & 0.843 & $0.340-$ & تساوي & 0.334 & 1.626 & الجوانب \\
\hline غعنوية & 0.245 & 1.016 - & تساوي & 0.112 & 2.674 & الاستمرارية \\
\hline
\end{tabular}

يتضح من الجدول رقم (10) ما يلي:

- وجود اختلافات جوهرية ذات دلالة إحصائية بين

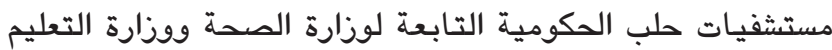

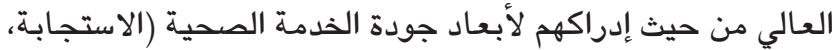

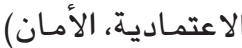

- علدم وجود اختلافات جوهرية ذات دلالة إحصائية بين

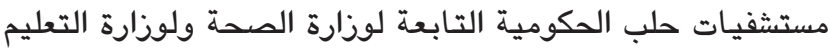
العالي من حيث إدراكهم لأبعاد جودة الخدمة الصحية (التعاطفة

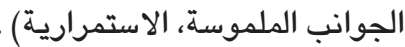

ويناءً على نتائج التحليل الإحصائي: يتم قبول الفرضية

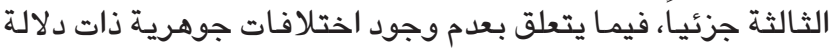

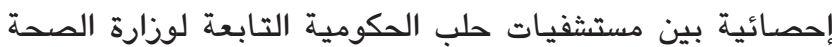

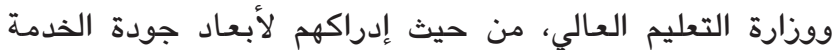

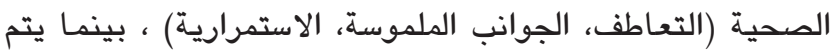

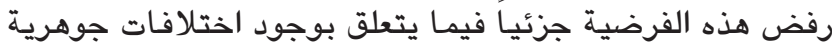

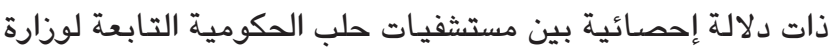

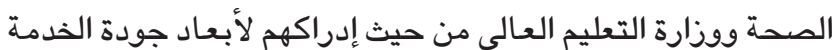
الصحية (الاستجابة، الاعتمادية، الأمان) .

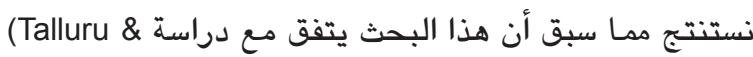

من حيث اعتماد الأبعاد الخمسة لجودة الخدمة دالثة

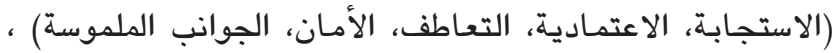

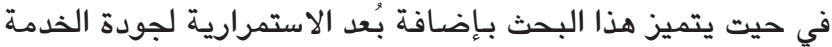

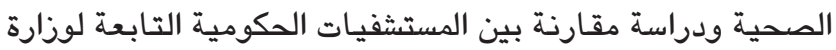
الصحة والتابعة لوزارة التعليم العالي.

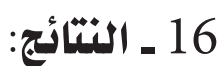

\section{لقد توصل الباحث إلى النتائج التالية}

1. وجود اختلافات جوهرية بين مقدمي الخدمة (أطباء،

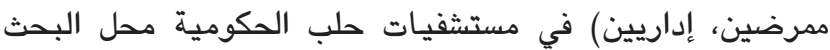

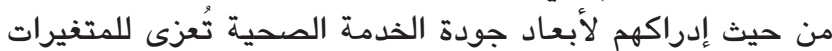
الديموغرافية التالية: (الجنس، العمر، سنوات الخبرة) .
' اختبار الفرضية الثالثة: لا توجد اختلافات جوهرية ذات دلالة إحصائية بين إدارة مستشفيات حلب الحكومية من

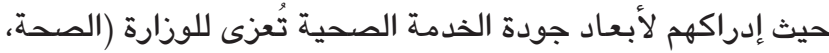

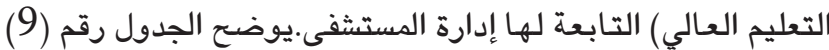
الإحصاءات الوصفية لأبعاد جودة الخدمة الصحية وذلك وفقاً لتابعية الستشفى لوزارة (الصحة أو التعليم العالي)

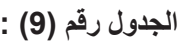

\begin{tabular}{|c|c|c|c|c|}
\hline الاجمالي & مستشفيات & مستشفيات & المتغيرات & الاحصاءات \\
\hline 174 & 86 & 88 & ----- & التكرار \\
\hline 3.89 & 3.86 & 3.92 & الاستجابة & \\
\hline 360 & 3.55 & 3.65 & الاعتمادية & \\
\hline 4.12 & 4.11 & 4.13 & التعاطف & \\
\hline 3.64 & 3.58 & 3.70 & الأمـان & ل الوسط \\
\hline 3.45 & 3.46 & 3.44 & الجوانب الملموسة & \\
\hline 3.77 & 3.79 & 3.75 & الاستمرارية & \\
\hline 3.75 & 3.73 & 3.77 & أبعاد جودة الخدمة & \\
\hline
\end{tabular}

$$
\text { يتضح من الجدول رقم (9) ما يلي: }
$$

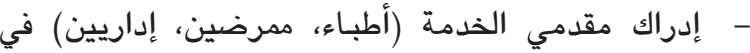

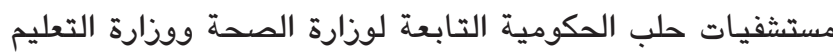
العالي كان أكبر من الدرجة المتوسطة حيث بلغت (3.75) . ـ - الدستشفيات التابعة لوزارة الصحة أكثر إدراكاً لأبعاد

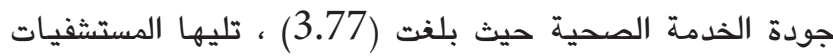
التابعة لوزارة التعليم العالي حيث بلغت (3.73)

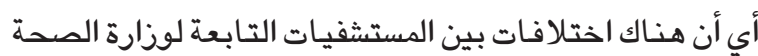

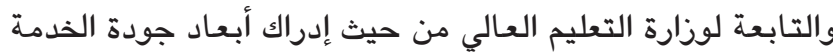

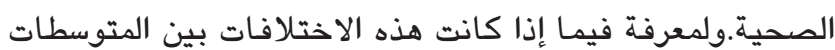
جوهرية أم لا حسب التابعية (وزارة الصحة، وزارة التعليم العالي)

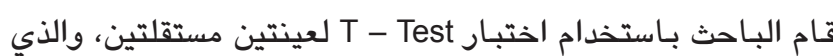

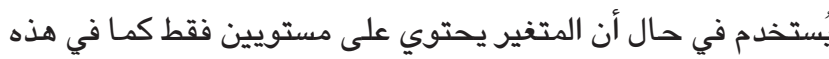

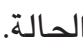

ويوضح الجدول رقم (10) نتائج اختبار Test - لأبعاد جودة الخدمة الصحية حسب التبعية (وزارة الصحة، وزارة التعليم

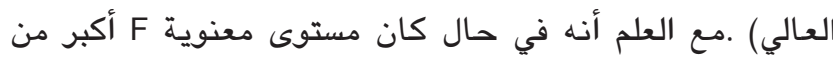
(0.05) نستخدم اختبار T في حال تساوي تباين العينتين، أما إذا كنا

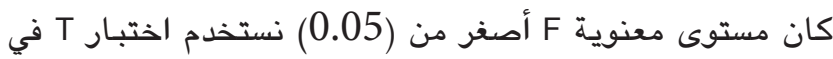
حال عدم تساوي تباين العينتين. 
الأولية. دار الشروق للنشر والتوزيع، عمان، الأردن.

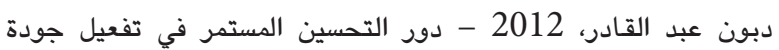

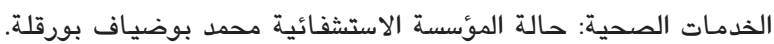
مجلة الباحث، العدد 11، 218 - 219.

ذياب صلاح محمود، 2012 - قياس أبعاد جودة الخدمات الطبية المقدمة

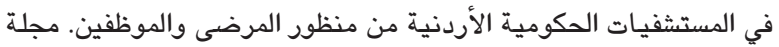
الجامعة الإسلامية للدراسات الاقتصادية والإدارية، الدجلد 20، العدد 1، 1 الإنية . $104-69$ عبد القادر محمد نور الطاهر أحمد، 2015 - قياس جودة الخدمات

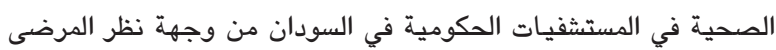

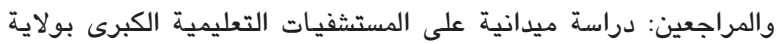
الخرطوم. المجلة الأردنية في إدارة الأعمال، المجلد 11، العرات العدد 4، 899

على محمد فتحي، 1994 - الإحصاء وبحوث العمليات. مكتبة جامعة عين شمس بـالقاهرة، مصر.

9. ماضي محمد توفيق، 2002 - تطبيقات إدارة الجودة الشاملة في الهنظمات الخدمية في مجال الصحة والتعليم: نموذج مفاهيمي مقترح. المنظمة العربية للتنمية الإدارية، 84.

10. مخيمر عبد العزيز، الطعامنة محمد، 2003 - الاتجاهـات الحديثة في إدارة

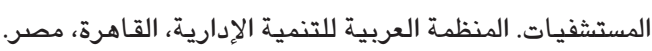

2 ـ المراجع الأجنبية:

1. GUPTA D, DENTON B., 2008 - Appointment Scheduling in Health Care: Challenges and Opportunities. IIE Transactions, 40, 800 - 819 .

2. JANET A, BROWN R. N., 2009 - The Healthcare Quality Handbbok: A Professional Resource \& Study Guide, 23rd Edition.

3. LIM P, TANG N., 2000 - A Study of Patient Expectations and Satisfaction in Singapore Hospitals. International Journal of Healthcare Quality Assurance, 13 (7), 290 - 299.

4. Qvretveil J (2000) , TQM in European Healthcare, International Journal of Healthcare Quality Assurance, 13 (2). 75 .

5. TALLURU S, PRASAD G. , 2003 - Patient Satisfaction: A Comparative Study. Journal of the Academy of Hospital Administration, 1s, 7 - 12.
2. وجود اختلافات جوهرية بين مقدمي الخدمة (أطباء،

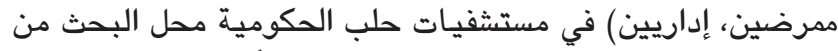

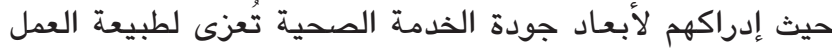

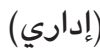

3. وجود اختلافات جوهرية ذات دلالة إحصائية بين 6

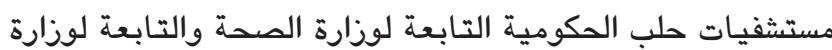

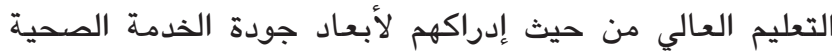

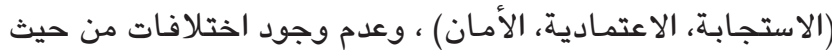
إدراكهم للأبعاد (التعاطف، الجوانب الملموسة، الامسان، واستمرارية) .

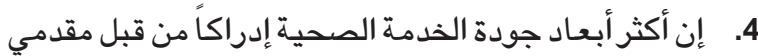

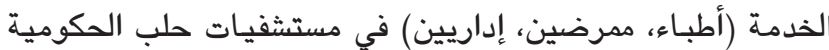
محل البحث هو بُعد التعاطف يليه الاستجابة، ثم الاستمرارية ثم الأمان ثم الاعتمـادية وأخيراً الجوانب الملموسة.

5. إن إدراك إدارة مستشفيات حلب الحكومية محل البحث

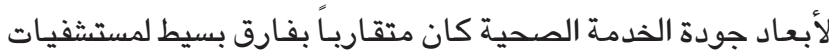
حلب الحكومية التابعة لوزارة الصحة.

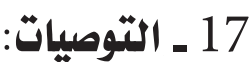
يوصي الباحث بما يلي:

1. قيام الإدارات في مستشفيات حلب الحكومية بندوات

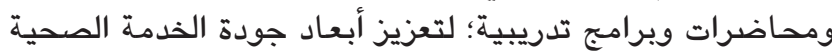

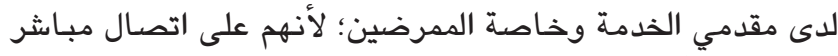

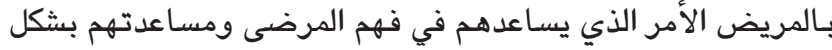

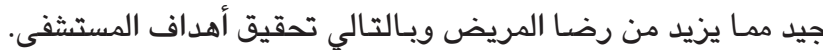

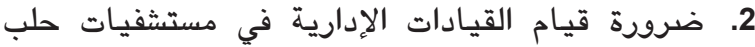

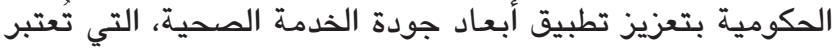

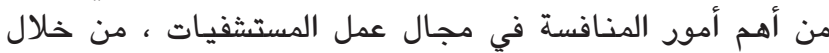
القرارات التي تصدرهـا لتطبيق أبعاد جودة الخدمة الصحية. 3. ضرورة قيام الإدارات في مستشفيات حلب الحكومية

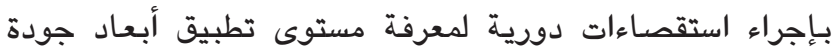

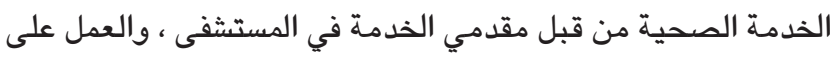
تلافي التقصير في حال وجوده.

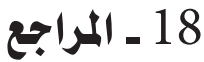

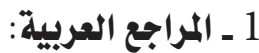

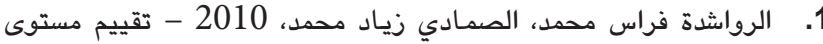
الخدمات من وجهة نظر المستفيدين من التأمين الصحي في الأردن. المجلة فئل

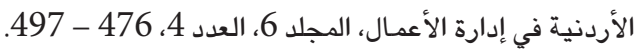

2. الفراج أسامة، 2009 - تقييم جودة الرعاية الصحية في مستشفيات

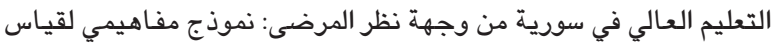

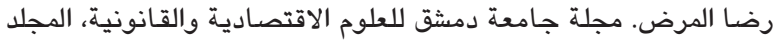

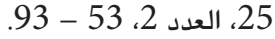

توفيق عبد الرحمن، 2007 - مبادئ جودة الخدمة. مركز الخبرات المهنية

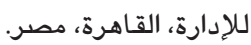
4. خوجة توفيق، 2003 - الدلدخل في تحسين الجودة للرعاية الصحية 